\title{
Green Synthesis and Characterization of Biosilica Produced from Sugarcane Waste Ash
}

\author{
Rodrigo Heleno Alves, ${ }^{1}$ Thais Vitória da Silva Reis, ${ }^{1,2}$ \\ Suzimara Rovani, ${ }^{1}$ and Denise Alves Fungaro ${ }^{1}$ \\ ${ }^{1}$ Instituto de Pesquisas Energéticas e Nucleares (IPEN-CNEN/SP), Av. Prof. Lineu Prestes, No. 2242, Cidade Universitária, \\ 05508-000 São Paulo, SP, Brazil \\ ${ }^{2}$ Faculdades Oswaldo Cruz, Rua Brigadeiro Galvão, 540 Barra Funda, 01151-000 São Paulo, SP, Brazil
}

Correspondence should be addressed to Denise Alves Fungaro; dafungaro@gmail.com

Received 13 February 2017; Revised 4 April 2017; Accepted 26 April 2017; Published 21 May 2017

Academic Editor: Barbara Gawdzik

Copyright (C) 2017 Rodrigo Heleno Alves et al. This is an open access article distributed under the Creative Commons Attribution License, which permits unrestricted use, distribution, and reproduction in any medium, provided the original work is properly cited.

In this study, ash from sugarcane waste was used in the synthesis of biosilica using alkaline extraction followed by acid precipitation. Different parameters that could influence the silica particle synthesis were evaluated. The ash and synthesized biosilica were characterized by a combination of spectroscopic and chemical techniques such as XRD, XRF, SEM, particle size analyser, $\mathrm{N}_{2}$ adsorption analysis, TGA, and FTIR. The best condition for biosilica production was achieved with fusion method and aging temperature of $80^{\circ} \mathrm{C}$ for $1 \mathrm{~h}$ during gel formation. X-ray powder diffraction pattern confirms the amorphous nature of synthesized silica. The purity of the prepared silica was $99 \%$ silica which was confirmed by means of XRF. The experimental data suggest that the sugarcane waste ash could be converted into a value-added product, minimizing the environmental impact of disposal problems.

\section{Introduction}

Brazil is the global leader in the production of sugarcane, harvesting more than 600 million tonnes of it every year. The state of São Paulo, in the South-Central region, is the largest producer in the country and is responsible for $61 \%$ of Brazil's sugarcane production [1].

The processing of sugarcane to produce sugar and ethanol generates various agricultural wastes, especially straw and bagasse. Each ton of sugarcane generates between 250 and $270 \mathrm{~kg}$ of bagasse and $200 \mathrm{~kg}$ of straw and tips [2].

About $50 \%$ of these residues are used in distillery plants as a source of energy; the remainder is stockpiled. The burning of the waste generates $1-4 \%$ ash. Considering the amount of sugarcane produced in this harvest, between 3 and 12 million tons of ash are produced each year.

Generally, the destination of biomass ash generated in the sugar industry is the disposal in landfills or used as fertilizer in the plantations. These practices have caused problems to public health and unwanted environmental impacts mainly associated with soil and water [3]. Moreover, sugarcane waste ash can be used as a substitute for cement or sand in civil construction $[4,5]$.

The ash of the sugarcane waste contains high levels of silica [3]. Silica is considered a value-added product for presenting numerous applications in various industries like rubber industry as a reinforcing agent, in tooth pastes as a cleansing agent, as an anticaking agent in salts, in cosmetics, and so forth [6]. Thus, efforts have been done in order to find economical way to extract silica of waste ash materials.

The objective of this study was to evaluate the effect of different synthesis parameters to optimize conditions for obtaining biosilica from sugarcane biomass ash. This not only provides value addition but also solves the problem of large amount of ash disposal.

\section{Experimental}

2.1. Materials. All the regents used were of analytical grade. Sodium hydroxide and acetic acid (analytical grade) were 
TABLE 1: Parameters of the biosilica synthesis process.

\begin{tabular}{|c|c|c|c|c|c|c|c|}
\hline \multirow{2}{*}{ Samples } & \multicolumn{2}{|c|}{ Alkaline fusion } & \multicolumn{2}{|c|}{ Hydrothermal treatment } & \multicolumn{3}{|c|}{ Silica gel } \\
\hline & Time (h) & Agitation time (h) & Time (h) & Temperature $\left({ }^{\circ} \mathrm{C}\right)$ & Silica gel formation & $m^{\mathrm{a}}(\mathrm{g})$ & Synthesis product \\
\hline BS1 & 1 & 24 & 1 & 100 & No & - & - \\
\hline BS2 & 1 & 24 & 2 & 100 & Yes & 0.232 & Amorphous \\
\hline BS3 & 1 & 24 & 3 & 100 & Yes & 0.248 & Amorphous \\
\hline BS4 & 1 & 24 & 6 & 100 & Yes & 0.366 & Amorphous \\
\hline BS5 & 1 & 24 & 20 & 100 & Yes & 0.431 & Amorphous \\
\hline BS6 & 1 & 24 & 24 & 100 & Yes & 0.475 & $\mathrm{n} \cdot \mathrm{a}^{\mathrm{b}}$ \\
\hline BS7 & 0 & 0 & 3 & 100 & No & - & - \\
\hline BS8 & 1 & 24 & 2 & 90 & Yes & 0.388 & n.a $\mathrm{a}^{\mathrm{b}}$ \\
\hline BS9 & 1 & 24 & 3 & 90 & Yes & 0.402 & Amorphous \\
\hline BS10 & 1 & 24 & 6 & 90 & Yes & 0.530 & Amorphous \\
\hline BS11 & 1 & 24 & 20 & 90 & Yes & 0.689 & Amorphous \\
\hline $\mathrm{BS} 12^{\mathrm{c}}$ & 1 & 24 & 20 & 90 & Yes & 0.742 & Amorphous \\
\hline
\end{tabular}

${ }^{\mathrm{a}} m=$ mass of product formed; ${ }^{\mathrm{b}} \mathrm{n} . \mathrm{a}=$ not totally amorphous; ${ }^{\mathrm{c}} \mathrm{BS} 12=$ aging temperature of $80^{\circ} \mathrm{C}$.

obtained from Merck (Darmstadt, Germany). The sample of ash derived from burning of the sugarcane waste was provided by the company COSAN S.A. (São Paulo, Brazil). Quantitative filter paper Whatman Number 41 was purchased from Whatman Plc (Kent, England). Oven (Fanen Orion 515 Model), muffle furnace (Quimis, Q-318 M24 Model), and mechanical shaker (Ethik Technology 430 Model) were used.

2.2. Methods. The synthesis of biosilica was carried out by different methods. A schematic flow chart for preparation of silica gel from sugarcane waste ash (SWA) is proposed as shown in Figure 1. The experimental conditions are summarized in Table 1.

2.2.1. Preparation of Sodium Silicate Solution by Two-Step Process. Typically, $1.0 \mathrm{~g}$ of SWA was mixed with $1.3 \mathrm{~g}$ of $\mathrm{NaOH}$ in capsule and triturated to obtain a homogeneous mixture. This mixture was then calcined at $550^{\circ} \mathrm{C}$ for $1 \mathrm{~h}$ in a muffle furnace. After cooling to room temperature, the fusion products were ground and placed in beaker with $100 \mathrm{~mL}$ of distilled water. The suspension was stirred for $24 \mathrm{~h}(120 \mathrm{rpm})$ at room temperature. The resulting slurry of first step was submitted to hydrothermal treatment in an oven at different temperatures $\left(90\right.$ and $100^{\circ} \mathrm{C}$ ) and reaction times (1-24 h). The reaction products were filtered with a quantitative filter paper Whatman Number 41 and the filtered liquid (sodium silicate solution) was stored for biosilica preparation.

2.2.2. Preparation of Sodium Silicate Solution by One-Step Process. In a Teflon beaker, $1.0 \mathrm{~g}$ of SWA was mixed with $10 \mathrm{~mL}$ of $3 \mathrm{~mol} \mathrm{~L}^{-1}$ aqueous $\mathrm{NaOH}$ solution. The mixture was incubated at $100^{\circ} \mathrm{C}$ in oven for $3 \mathrm{~h}$. At the end of the treatment, the mixture was filtered and the filtered liquid was allowed to cool to room temperature and was stored.

2.2.3. Synthesis of Biosilica. In the as-obtained solution of sodium silicate, $3 \mathrm{~mol} \mathrm{~L}^{-1}$ acetic acid was added dropwise under constant stirring until $\mathrm{pH}$ 7. The silica gel formed was

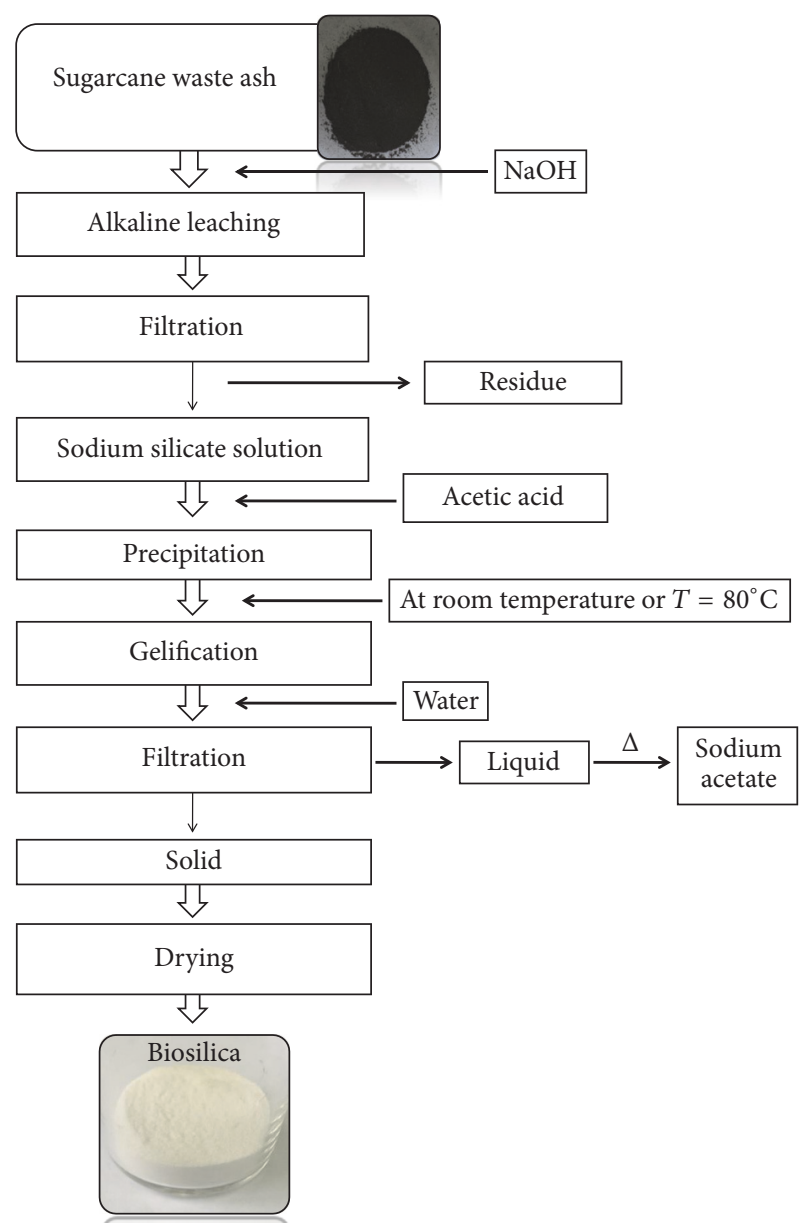

FIGURE 1: Flow diagram of the procedure used to produce biosilica from sugarcane biomass ash.

aged for at least $20 \mathrm{~h}$ at room temperature. After this time, the silica gel was washed with distilled water and filtered. The filtrate was stocked and the silica retained on the filter was dried for $24 \mathrm{~h}$ at $80^{\circ} \mathrm{C}$ [7-10]. 
2.2.4. Synthesis of Biosilica with Aging Process at $80^{\circ} \mathrm{C}$. The sodium silicate solution was obtained using the two-step process described in Section 2.2.1. The conditions used in the second step were $90^{\circ} \mathrm{C}$ for $20 \mathrm{~h}$. In the sodium silicate solution $3 \mathrm{~mol} \mathrm{~L}^{-1}$ acetic acid up was added to $\mathrm{pH}$ 7. The resulting gel mixture was aged at $80^{\circ} \mathrm{C}$ for $1 \mathrm{~h}$ (aging step). The gel was washed twice with $100 \mathrm{~mL}$ of distilled water, filtered (sodium acetate solution), and separated from solid (silica gel). The silica gel was dried at $135^{\circ} \mathrm{C}$ for $24 \mathrm{~h}$ [11]. The sodium acetate solution was dried at $100^{\circ} \mathrm{C}$ to obtain sodium acetate as salt.

2.3. Characterization of Materials. The chemical composition of materials in the form of oxides was analysed by energy dispersive X-ray fluorescence spectrometry (XRF) (RX Axios Advanced, PANalytical, Phillips spectrometer) and wavelength dispersive X-ray fluorescence spectroscopy (WDXRF) (Rigaku Co. spectrometer, model RIX 3000). The mineralogical compositions of the samples were determined by X-ray diffraction analyses (XRD) with an automated Rigaku multiflex diffractometer with $\mathrm{Cu}$ anode using $\mathrm{Co}$ $\mathrm{K} \alpha$ radiation at $40 \mathrm{kV}$ and $20 \mathrm{~mA}$ over the range $(2 \theta)$ of $5-80^{\circ}$ with a scan time of $0.5^{\circ} / \mathrm{min}$. The crystalline phases present in the samples were identified with the help of ICDD (International Centre for Diffraction Data). The Fourier transform infrared spectroscopy (FTIR) spectra were recorded on ALPHA FTIR Spectrometer from Bruker, operating in attenuated total reflectance (ATR). The spectra were obtained using 200 cumulative scans, range 375 to $4000 \mathrm{~cm}^{-1}$. Scanning electron micrograph was obtained by a JEOL JSM-7401 scanning electron microscope, at a typical acceleration voltage of $3 \mathrm{KV}$. The particle size analysis was conducted by laser particle analyser Malvern MSS Mastersizer 2000 Ver. 5.54 (United Kingdom) $(0.02-2000 \mu \mathrm{m})$ in isopropyl alcohol dispersing medium and pump speed of $2500 \mathrm{rpm}$. Adsorption-desorption isotherms were measured with Micrometrics TriStar volumetric adsorption analyser using nitrogen of $99.999 \%$ purity. Measurements were performed in range of relative pressure from 10E-6 to 0.99 liquid nitrogen on the samples degased for $2 \mathrm{~h}$, under vacuum about $50 \mathrm{mTorr}$, at $200^{\circ} \mathrm{C}$. The specific surface area and average pore diameter were evaluated using BET method. The total pore volume was estimated from the amount of nitrogen adsorbed at the relative pressure of 0.99 . Thermogravimetric analyses were recorded in a thermogravimetric analyser TGA/SDTA 851 produced by Mettler Toledo. Dried samples ( 10.0 mg) were analysed under dynamic nitrogen atmosphere with a flow of $100.0 \mathrm{~mL} \mathrm{~min}^{-1}$, using a alumina-port sample heated $1000^{\circ} \mathrm{C}$ with a heating rate of $5^{\circ}$ or $10^{\circ} \mathrm{C} \mathrm{min}^{-1}$. Determination of carbon and sulfur was done by LECO model TCHEN600. Other physical-chemical properties (bulk density, cation exchange capacity, $\mathrm{pH}$, and $\mathrm{pH}$ of point of zero charge) have been described in a previous paper [12].

\section{Results and Discussion}

3.1. Characterization of Sugarcane Waste Ash. The chemical composition of sugarcane waste ash (SWA) is shown in Table 2. The major component was $\mathrm{SiO}_{2}$ content with $81.60 \mathrm{wt} \%$., indicating that this material is suitable to use
TABLE 2: Chemical composition of sugarcane waste ash and synthesized biosilica.

\begin{tabular}{lcc}
\hline Oxides & SWA (wt.\%) & Biosilica (wt.\%) \\
\hline $\mathrm{SiO}_{2}$ & 81.60 & 99.1 \\
$\mathrm{Al}_{2} \mathrm{O}_{3}$ & 7.94 & 0.33 \\
$\mathrm{Fe}_{2} \mathrm{O}_{3}$ & 2.31 & 0.08 \\
$\mathrm{~K}_{2} \mathrm{O}$ & 2.10 & 0.07 \\
$\mathrm{MgO}$ & 1.26 & - \\
$\mathrm{P}_{2} \mathrm{O}_{5}$ & 1.07 & - \\
$\mathrm{CaO}$ & 0.98 & 0.03 \\
$\mathrm{TiO}_{2}$ & 0.67 & - \\
$\mathrm{SO}_{3}$ & 0.52 & - \\
$\mathrm{Cl}$ & 0.36 & 0.13 \\
$\mathrm{Na}_{2} \mathrm{O}$ & 0.26 & 0.22 \\
$\mathrm{MnO}_{\mathrm{Ta}} \mathrm{O}_{5}$ & 0.06 & - \\
$\mathrm{NiO}_{\mathrm{As}} \mathrm{O}_{3}$ & 0.04 & - \\
$\mathrm{CuO}$ & 0.03 & 0.03 \\
$\mathrm{ZnO}_{\mathrm{LI}}^{\mathrm{a}}$ & 0.03 & - \\
\hline & - & $<0.01$ \\
$\mathrm{LI}$ & - & $<0.01$ \\
\hline
\end{tabular}

${ }^{\mathrm{a}} \mathrm{LI}=$ loss on ignition at $1050^{\circ} \mathrm{C}$ for one hour.

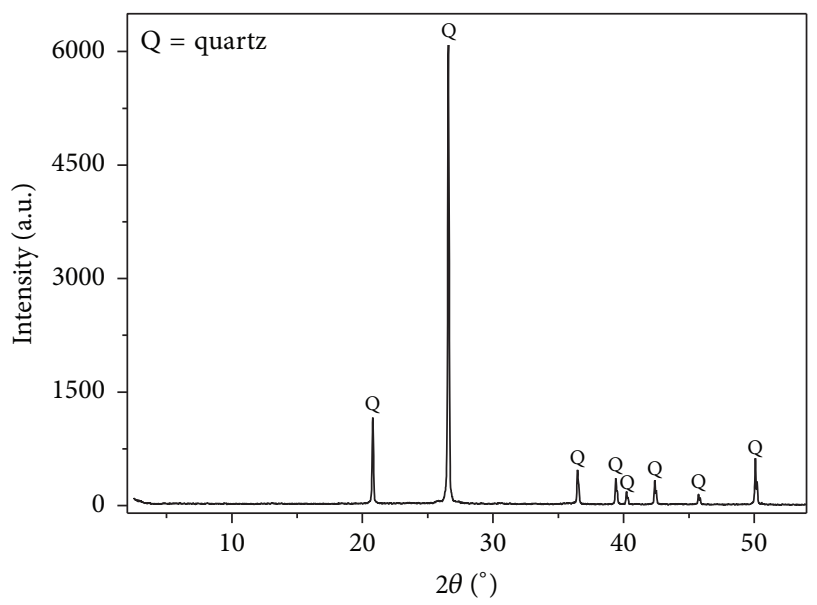

FIGURE 2: X-ray diffractogram of sugarcane biomass ash.

as a source of silica for producing sodium silicate solution. The compounds of aluminum, iron, potassium, and magnesium were found in amounts $\geq 1.3 \%$. The other oxides were considered impurities for presenting content $\leq 1.00 \%$. The percentage of carbon and sulfur was 0.16 and $0.04 \%$, respectively.

The sugarcane absorbs more silicon than any other cultivated plant. Sugarcane can remove from 500 to $700 \mathrm{~kg} \mathrm{Si} \mathrm{ha}^{-1}$ during their development [13]. Monosilicic acid $\left(\mathrm{H}_{4} \mathrm{SiO}_{4}\right)$ is the form of silicon used by plants, which is found in both liquid and adsorbed phases of silicon in soils [14-17].

The SWA diffractogram (Figure 2) indicated the presence of silica only in the crystalline phase $\left(\mathrm{SiO}_{2}, \mathrm{ICDD} 01-\right.$ 085-0794). The peaks observed at $20.9^{\circ}, 26.6^{\circ}, 36.5^{\circ}, 39.4^{\circ}$, 


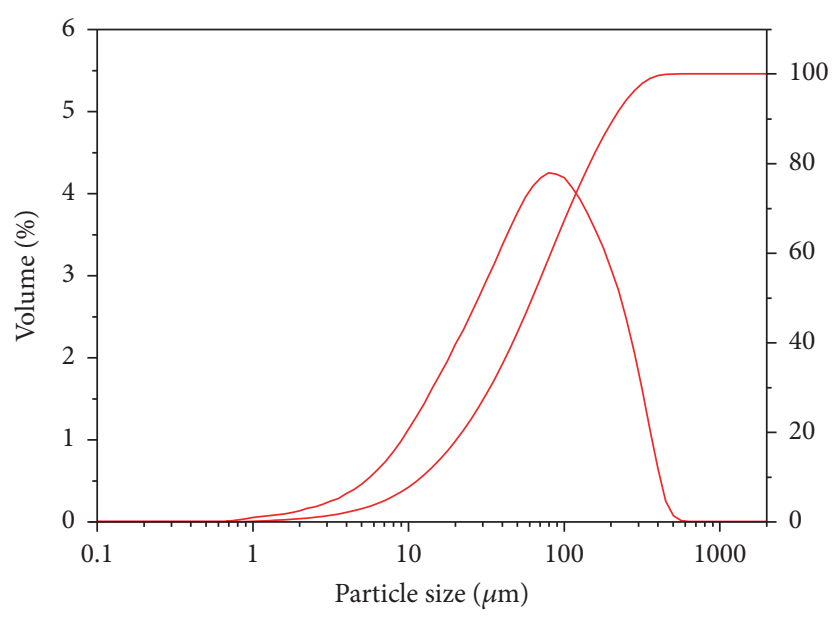

FIGURE 3: Particle size distribution curves of sugarcane biomass ash.

$40.2^{\circ}, 42.4^{\circ}, 45.8^{\circ}$, and $50.2^{\circ}$ are typical of quartz. The crystalline phase of silica in the sugarcane ash is related to the conditions of combustion (mainly time and temperature). At temperatures of $500-800^{\circ} \mathrm{C}$ or when the exposure to high temperature is small, the silica contained in the ash is predominantly amorphous. At temperatures greater than $800^{\circ} \mathrm{C}$, the amorphous silica present in sugarcane is converted in crystalline silica polymorphs, such as quartz, cristobalite, and tridymite [18].

The discrete particle diameter distribution and the cumulative distribution of SWA were shown in Figure 3. The diameters corresponding to the cumulative distribution in the contents of $10.0 \%, 50.0 \%$, and $90.0 \%\left(d_{0.1}, d_{0.5}, d_{0.9}\right.$, resp.) and Sauter mean diameter $(d[3,2])$ presented the following values: $12.170,62.528,208.140$, and $26.084 \mu \mathrm{m}$, respectively. The range of the estimated particle size was between 0.893 and $563.677 \mu \mathrm{m}$.

3.2. X-Ray Diffraction Analysis of Biomass Ash-Based Products. Tests were performed using different experimental conditions in order to determine the optimal conditions of synthesis for obtaining the biosilica. The broad X-ray diffraction peak at theta equal to 22 degrees confirms the formation of amorphous silica, in general [7]. The results are summarized in Figures 4 and 5. The yield of the synthesis was estimated using the mass of the actual product obtained (Table 1).

In the set of experiments at $100^{\circ} \mathrm{C}$ (Table 1, BS1-BS7 samples, Figure 4), XRD showed that the extracted silica is predominantly amorphous for BS2 to BS5 samples. For shorter reaction time $(1 \mathrm{~h})$ there was no gel formation (BS1 sample). A difference in the patterns of diffraction was recognized after $24 \mathrm{~h}$ of hydrothermal treatment due to the formation of only crystalline material (BS6 sample). There was no gel formation in BS7 sample, and therefore it did not form silica. This fact suggests that the alkaline fusion method should be applied to transform the high crystalline silica content of SWA in sodium silicate solution prior to the hydrothermal step.

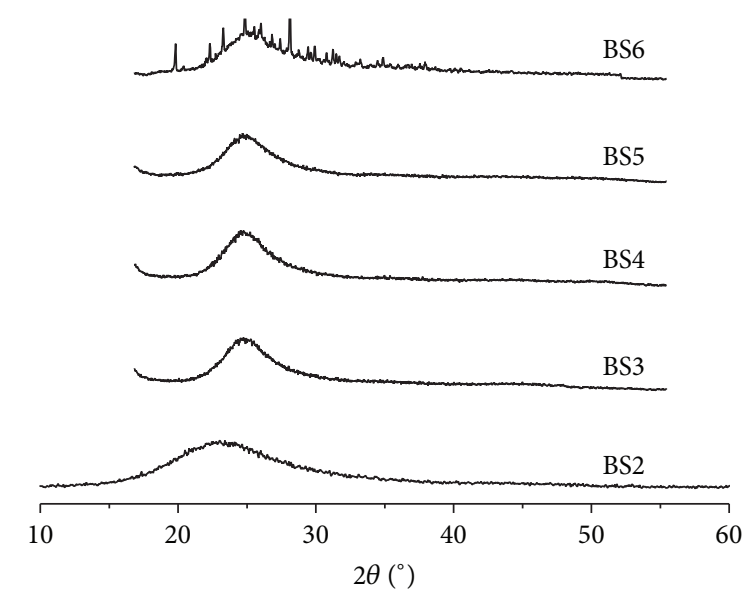

FIGURE 4: XRD patterns of the synthesis products obtained by hydrothermal treatment of sugarcane waste ash at $100^{\circ} \mathrm{C}$.

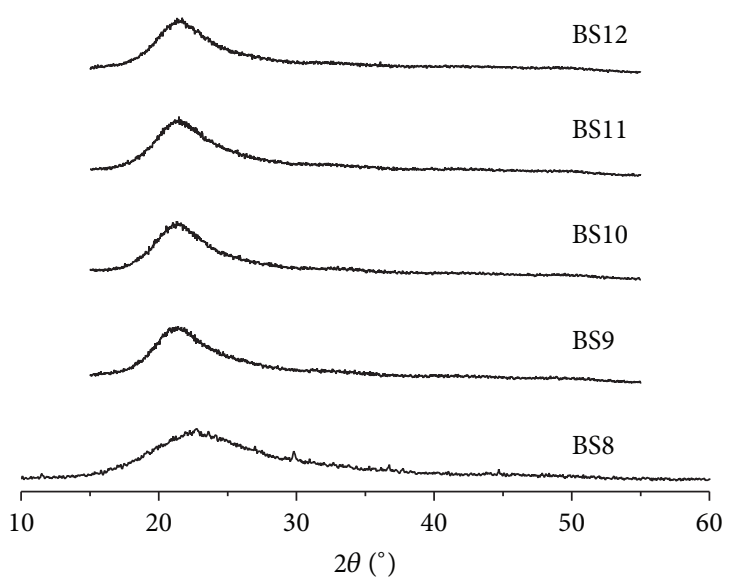

FIGURE 5: XRD patterns of the synthesis products obtained by hydrothermal treatment of sugarcane waste ash at $90^{\circ} \mathrm{C}$.

In the set of experiments at $90^{\circ} \mathrm{C}$ (Table 1, BS8-BS12, Figure 5), essentially noncrystalline (amorphous) biosilica was formed (except BS8 sample) with yield directly proportional to the time of hydrothermal treatment. XRD of BS8 sample show amorphous silica along with some crystalline silica.

The greatest silica yield (91\%) was obtained for the synthesis with aging process at $80^{\circ} \mathrm{C}$ (BS12 sample). Furthermore, the gelation time presented a drastic reduction (at least $20 \mathrm{~h}$ for $1 \mathrm{~h}$ ) and the synthesis was reproducible. Aside from biosilica xerogel, $1.663 \mathrm{~g}$ of sodium acetate can also be derived from synthesis through evaporation of the aqueous solution (Figure 1). Thus, besides the mineralogical analysis, other characterizations were carried out for the silica gel obtained by this experimental procedure.

\subsection{Characterization of Biosilica Gel}

3.3.1. Physical and Chemical Characteristics. X-Ray fluorescence showed that the produced biosilica had high purity (99.1\%), free of $\mathrm{MgO}, \mathrm{P}_{2} \mathrm{O}_{5}, \mathrm{TiO}_{2}, \mathrm{SO}_{3}, \mathrm{MnO}, \mathrm{Ta}_{2} \mathrm{O}_{5}$, and 


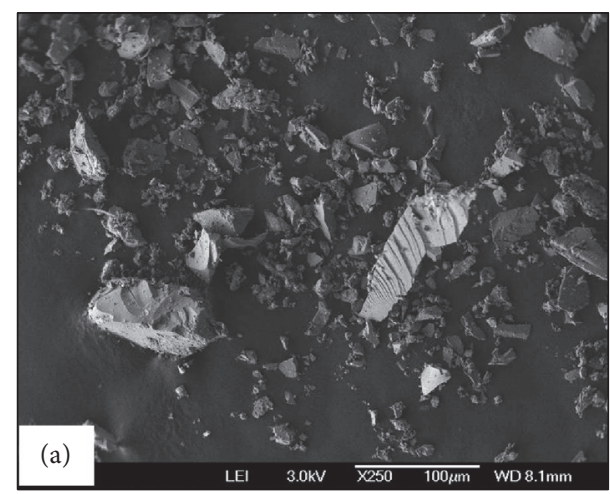

(a)

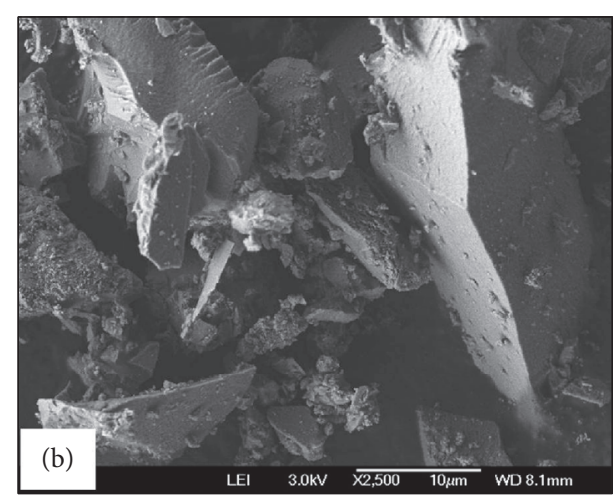

(b)

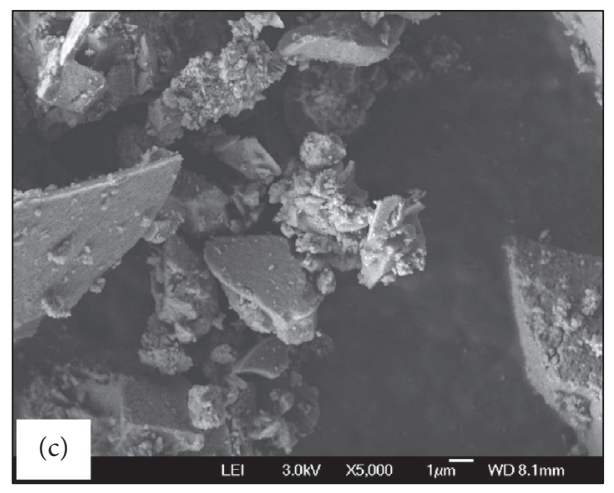

(c)

Figure 6: Scanning electron microscopy of biosilica. Magnification of 250x (a), 2500x (b), and 5000x (c).

TABLE 3: Physical-chemical properties of biomass ash and biosilica.

\begin{tabular}{lcc}
\hline & SWA & Biosilica \\
\hline $\mathrm{pH}$ & 5.70 & 7.80 \\
$\mathrm{pH}_{\text {PZC }}{ }^{\mathrm{b}}$ & - & 5.29 \\
$\mathrm{CEC}^{\mathrm{a}}$ (meq 100 g) & - & 4.25 \\
Bulk density $\left(\mathrm{g} \mathrm{cm}^{-3}\right)$ & 1.41 & 0.708 \\
\hline
\end{tabular}

${ }^{\mathrm{a}} \mathrm{CEC}=$ cationic exchange capacity; ${ }^{\mathrm{b}} \mathrm{pH}_{\mathrm{PZC}}=$ point of zero charge.

$\mathrm{As}_{2} \mathrm{O}_{3}$ that were present in the sugarcane waste ash (Table 2). Also, minor amounts of $\mathrm{Na}_{2} \mathrm{O}, \mathrm{Al}_{2} \mathrm{O}_{3}$, and $\mathrm{Cl}$ and traces of $\mathrm{Fe}, \mathrm{K}, \mathrm{Ca}, \mathrm{Ni} \mathrm{Cu}$, and $\mathrm{Zn}$ were found in synthesized material. Some impurities were resulting from the sodium hydroxide used in the synthesis. The high purity was obtained after washing the silica gel (B12 sample) repeatedly with deionized water to remove sodium salt [8-10].

The other physical-chemical properties of biosilica and the ash that served as raw material are shown in Table 3. The $\mathrm{pH}$ of the leached of the ash is slightly acid and the $\mathrm{pH}$ of silica gel is slightly alkaline. To produce silica, it is necessary to add acid to silicate solution. When acid was added to silicate solution $(\mathrm{pH}>11)$, silica gel started to form rapidly as soon as $\mathrm{pH} 10$ was reached and formed a rigid gel at $\mathrm{pH} \sim 7.0$. The incomplete neutralization or the presence of residual $\mathrm{OH}^{-}$may be responsible for slightly alkaline $\mathrm{pH}$ of the leached biosilica. The surface of the biosilica has a negative charge in aqueous solution because the $\mathrm{pH}$ value is above the $\mathrm{pH}$ in the point of zero charge $\left(\mathrm{pH}_{\mathrm{PZC}}\right)$ indicating that is a material with cationic exchange capacity. The bulk density of the biosilica was lower than $1.3 \mathrm{~g} \mathrm{~cm}^{-3}$, showing that this product is classified as lightweight material. This property may be beneficial for the use of the prepared gel in many environmental and industrial applications [19].

3.3.2. Morphology Analysis of Silica Gel. The surface morphology of the biosilica was obtained using SEM images with different magnifications (Figure 6). The silica particles with size between $<1$ to $100 \mu \mathrm{m}$ were grouped into clusters, forming an irregular and cohesive surface. In addition, smooth surfaces were also observed. The agglomeration of particles forming clusters is a result of alkaline treatment and the lack of uniformity is a result of the laboratory grinding process.

3.3.3. Thermogravimetric Analysis. The thermogravimetry profiles of sugarcane waste ash (SWA), biosilica (BS), and biosilica repeatedly washed with water (BSW) are shown in Figure 7. For the BS and BSW sample, the first mass loss $\left(33-90^{\circ} \mathrm{C}\right)$ is ascribed to moisture loss [20]. The second mass loss $\left(90-180^{\circ} \mathrm{C}\right)$ corresponds to the loss of physically adsorbed water from the surface [21]. The third step $\left(180-530^{\circ} \mathrm{C}\right)$ was related to the loss of the organic structure $\left(\mathrm{CH}_{3} \mathrm{COONa}\right)$ 
TABLE 4: Assignments of the IR vibrations of studied samples.

\begin{tabular}{|c|c|c|c|}
\hline Frequency $\left(\mathrm{cm}^{-1}\right)$ & Assignment & Spectra of samples* & References \\
\hline 400 & Si-O-M (metal impurities bonding) & SWA & {$[26]$} \\
\hline $450-455$ & Si-O-Si symmetric stretching (siloxane group) & All samples & [23-25] \\
\hline 520 & Al-O-Si bending vibrations & SWA & {$[22]$} \\
\hline $550-560$ & (Si)-Al-O stretching & BS and BSW & [29] \\
\hline 615 & $\mathrm{CO}_{2}$ rocking (acetate group) & BS & {$[30]$} \\
\hline 645 & $\mathrm{CO}_{2}$ deformation torsion about $\mathrm{C}-\mathrm{C}$ bond (acetate group) & BS & {$[30]$} \\
\hline 690 & Si-O-Al deformation & SWA & {$[21]$} \\
\hline 780 & $\mathrm{Si}-\mathrm{O}$ stretching showed presence of quartz & SWA & {$[22]$} \\
\hline $790-797$ & Si-O-Si symmetric stretching (siloxane group) & BS and BSW & {$[24,25,27]$} \\
\hline 925 & C-C stretching (acetate group) & BS & {$[30]$} \\
\hline 957 & $\mathrm{Si}-\mathrm{OH}$ bending vibrational absorption (silanol group) & BSW & {$[25,27]$} \\
\hline $1050-1070$ & $\mathrm{Si}-\mathrm{O}-\mathrm{Si}$ asymmetric stretching & All samples & {$[23,25,31]$} \\
\hline 1415 & $\mathrm{C}-\mathrm{O}$ stretching (acetate group) & BS & {$[30]$} \\
\hline 1560 & C-O stretching (acetate group) & BS & {$[30]$} \\
\hline
\end{tabular}

* SWA = sugarcane waste ash; BS = biosilica; BSW = biosilica washed with water.

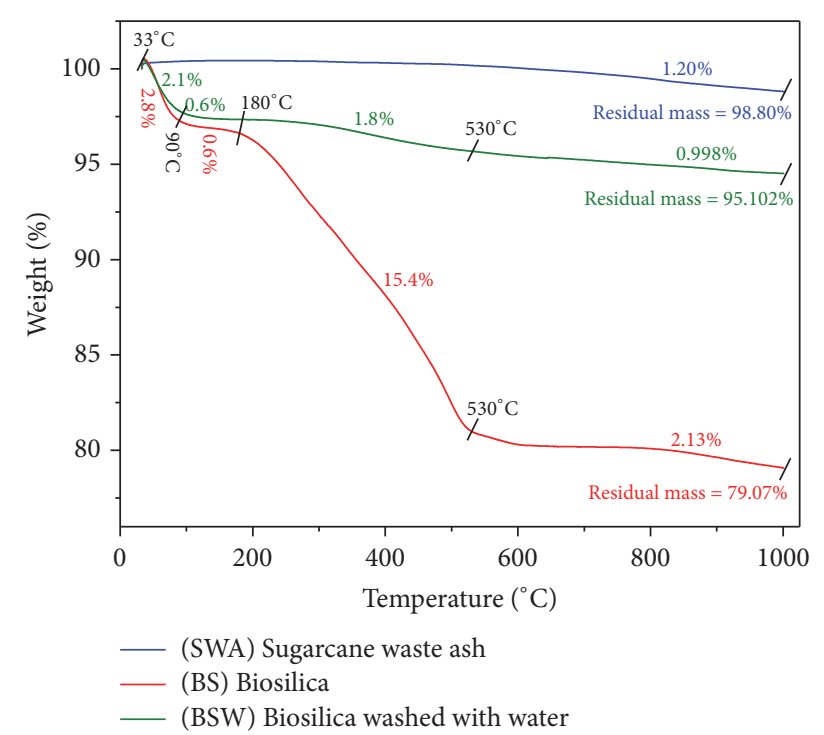

FIgURE 7: TG curves of SWA (blue), BS (red), and BSW (green) under an inert atmosphere of nitrogen.

and the loss of the chemically adsorbed water bonded to Si$\mathrm{OH}$ (silanol) through the hydrogen bond [21, 22]. The fourth weight loss $\left(530-1000^{\circ} \mathrm{C}\right)$ is due to the surface dehydroxylation reaction [22]. For the SWA, only a mass loss of $1.20 \%$ probably related to moisture loss was observed.

3.3.4. FTIR Analysis. The FTIR spectra of sugarcane waste ash (SWA), biosilica (BS), and biosilica after washing repeatedly with deionized water (BSW) are shown in Figures $8(\mathrm{a}), 8(\mathrm{~b})$, and $8(\mathrm{c})$, respectively. For all samples, the bands observed at about $450-455 \mathrm{~cm}^{-1}$ and $1050-1070 \mathrm{~cm}^{-1}$ were attributed to the Si-O-Si symmetric and asymmetric stretching, respectively [8, 23-25].
According to the literature, the bands observed at 400, 520,690 , and $780 \mathrm{~cm}^{-1}$ for SWA sample were due to Si-O$\mathrm{M}$ (metal impurities bonding), Al-O-Si bending vibrations, $\mathrm{Si}-\mathrm{O}$-Al deformation, and $\mathrm{Si}-\mathrm{O}$ stretching indicating the presence of crystalline quartz, respectively [21, 22, 26, 27]. These results are in agreement with chemical analysis (Table 2 ) and XRD patterns (Figure 2).

The appearance of absorption bands at 550 and $560 \mathrm{~cm}^{-1}$ assigned to the ( $\mathrm{Si})-\mathrm{Al}-\mathrm{O}$ stretching indicated the presence of small content of aluminum in BS and BSW samples [28]. Also, this is in agreement with chemical analysis.

The presence of band about $790-797 \mathrm{~cm}^{-1}$ for BS and BSW samples was due to Si-O-Si symmetric stretching [21, 29]. The bands at $615,645,925,1415$, and $1560 \mathrm{~cm}^{-1}$, for BS sample, were due to the presence of sodium acetate $\left(\mathrm{CH}_{3} \mathrm{COONa}\right)$, which is impurity of the synthesis process [30]. The absence of these peaks in BSW sample confirmed once again that the repeated washing step removes completely soluble salts of synthesized silica gel.

The band at $957 \mathrm{~cm}^{-1}$ for BSW sample is due to the presence of silanol group $\mathrm{Si}-\mathrm{OH}$ bending vibration absorption $[27,29]$. According to the TGA thermogram (Figure 7), BS sample also has the silanol group in its structure; however the silanol band was probably overlaid by the C-C stretching band at $925 \mathrm{~cm}^{-1}$. Table 4 shows FTIR assignments of the peaks observed in Figures 8(a), 8(b), and 8(c).

3.3.5. $\mathrm{N}_{2}$ Adsorption-Desorption Isotherms. Figure 9 presents the nitrogen adsorption/desorption isotherms measured at $77 \mathrm{~K}$ for the sugarcane waste ash and biosilica. The sugarcane waste ash exhibits a typical type II isotherm of nonporous materials according to the IUPAC classification (Figure 9(a)) $[31,32]$.

The isotherm obtained for BS (Figure 9(b)) was attributed to type IV, which is associated with a complex mesoporous structure where the distribution of pore size and shape were not well defined. In addition, the multilayer adsorption might 


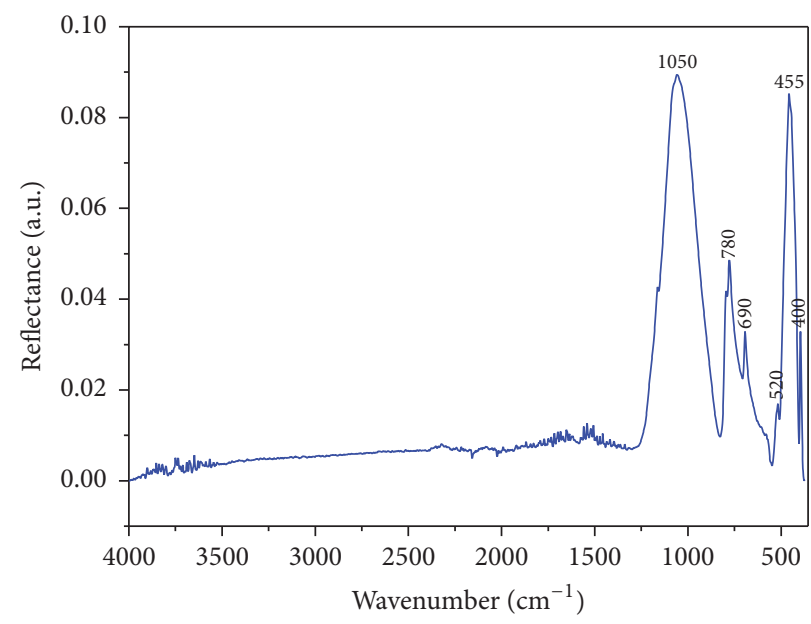

(a)

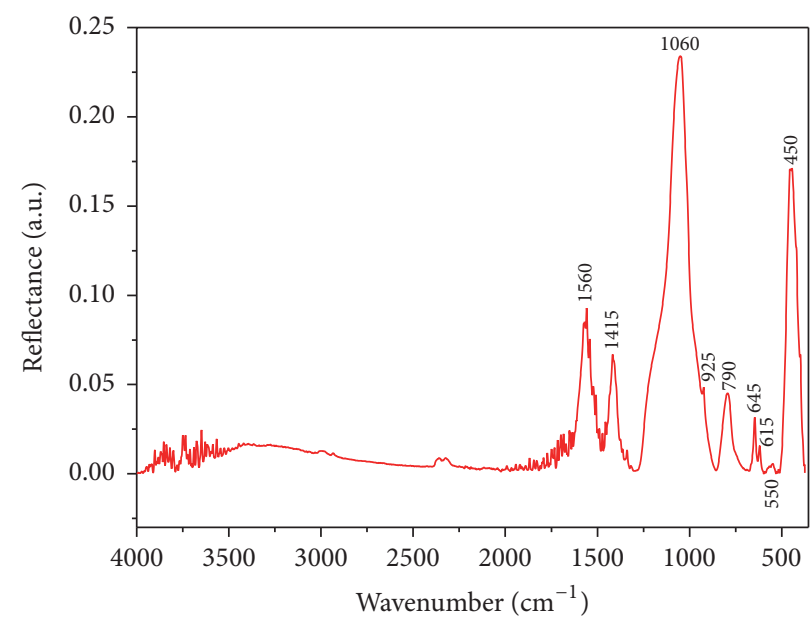

(b)

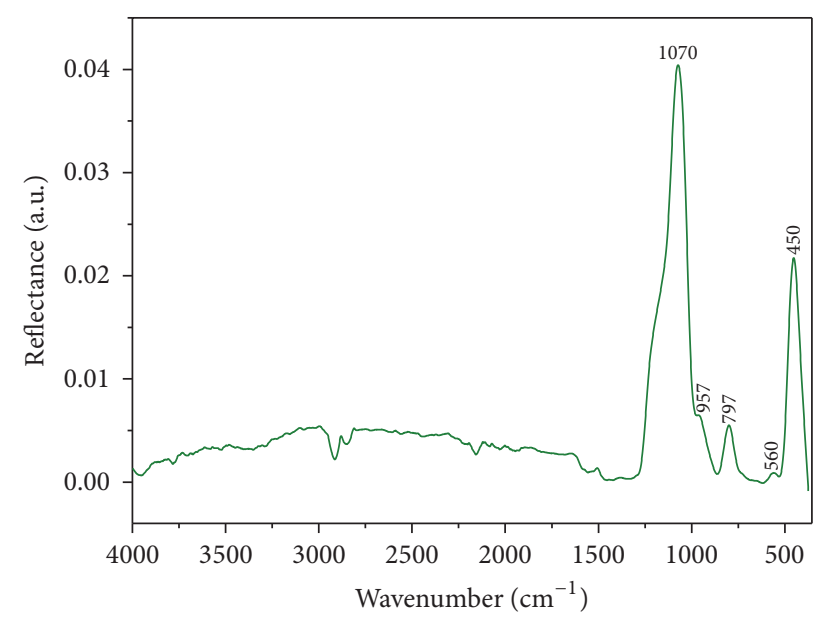

(c)

FIGURE 8: FTIR vibrational spectra for the samples: sugarcane waste ash (a), biosilica (b), and biosilica washed with water (c).

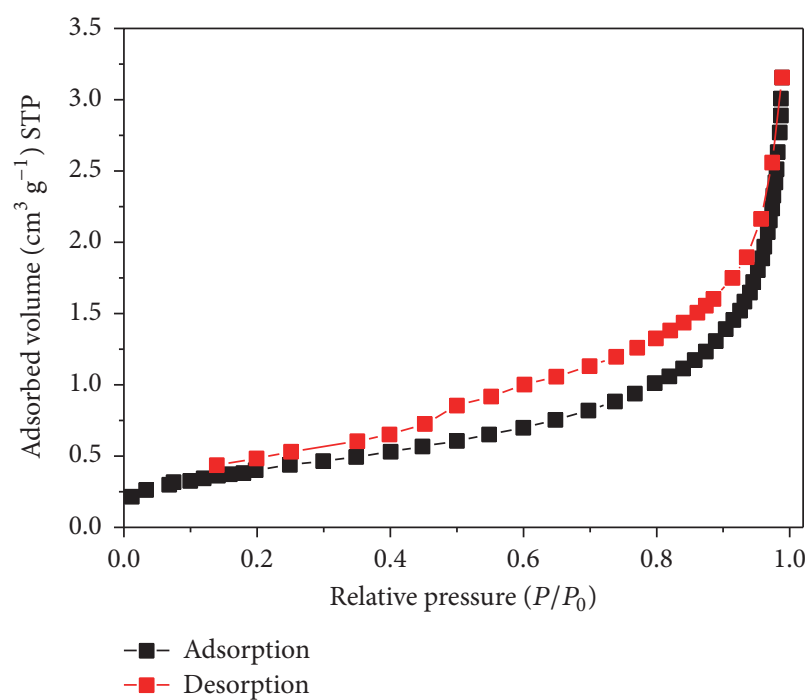

(a)

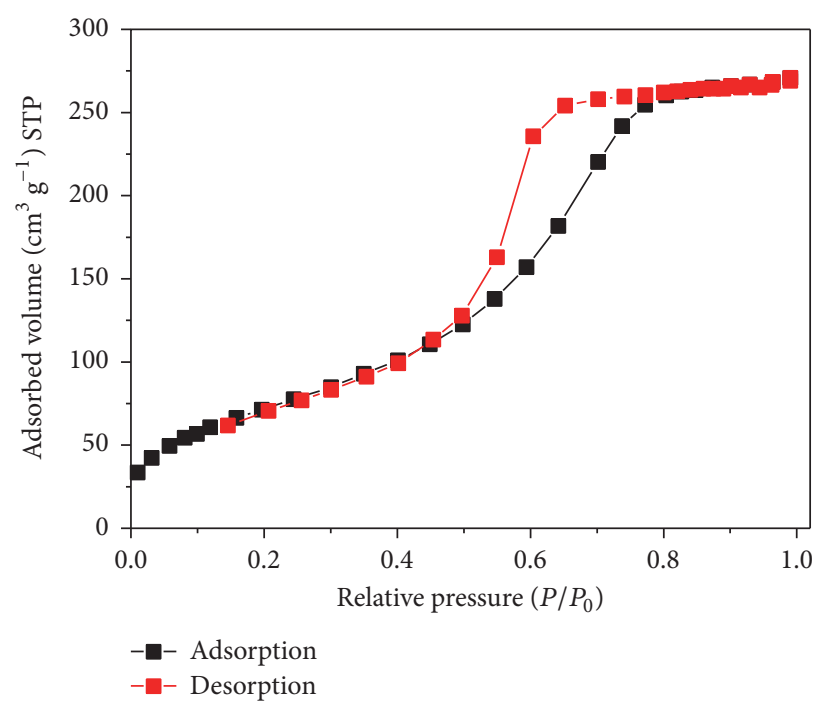

(b)

FIGURE 9: Nitrogen adsorption-desorption isotherms for the samples: ash (a) and biosilica (b). 
TABLE 5: Textural properties of biosilica and ash that serve as raw material.

\begin{tabular}{lccc}
\hline Samples & ${S_{\text {BET }}{ }^{\mathrm{a}}\left(\mathrm{m}^{2} \mathrm{~g}^{-1}\right)}$ & $V_{p}^{\mathrm{b}}\left(\mathrm{cm}^{3} \mathrm{~g}^{-1}\right)$ & $D_{p}{ }^{\mathrm{c}}(\mathrm{nm})$ \\
\hline Biosilica & 265 & 0.425 & 6.250 \\
Ash & 1.5 & 0.0049 & 10.790
\end{tabular}

${ }^{\mathrm{a}} S_{\mathrm{BET}}=$ specific area; ${ }^{\mathrm{b}} V_{p}=$ total pore volume; ${ }^{\mathrm{c}} D_{p}=$ average pore diameter.

occur in the middle relative pressure range. The desorption cycle of the isotherm displays a $\mathrm{H} 2$ type of the hysteresis loop, which is often associated with a complex mesoporous structure where the distribution of pore size and shape is not well defined $[33,34]$.

The surface area of all the materials was evaluated using BET method and the pore size by BJH method (isotherms with hysteresis), and their textural properties are summarized in Table 5. It is seen that the sugarcane waste ash shows low specific surface area and porosities. The synthesized silica showed high specific area with dimensions and pore volume within the specifications of mesoporous materials, which can also be proved by type IV isotherms, characterizing its mesoporosity in Figure 9.

\section{Conclusions}

Pure amorphous silica was successfully extracted at a $99.1 \%$ yield from sugarcane waste ash generated by a two-stage heating process followed by precipitation by acidification of the sodium silicate solution, so obtained. The XFR, FTIR, and $\mathrm{XRD}$ data gave clear evidence to the high purity of amorphous silica extracted from sugarcane waste ash. The use of the one-step process did not result in the formation of biosilica. Experimental results show that optimum conditions for producing biosilica were $90^{\circ} \mathrm{C}$ for $20 \mathrm{~h}$ in the hydrothermal treatment of two-step method, aging temperature of $80^{\circ} \mathrm{C}$, and an aging time of $1 \mathrm{~h}$. The mesoporous structure of silica makes it a potential catalytic (or catalyst support) or adsorbent material.

\section{Conflicts of Interest}

The authors declare that there are no conflicts of interest regarding the publication of this paper.

\section{Acknowledgments}

The authors are grateful to Conselho Nacional de Desenvolvimento Científico e Tecnológico (CNPq) and Coordenação de Aperfeiçoamento de Pessoal de Nível Superior (CAPES) for financial support, Dr. Paola Corio and Dr. Jonnatan J. Santos (Institute of Chemistry, USP) for SEM and FTIR-ATR analysis, Dr. M. A. Logli for nitrogen adsorption desorption isotherms analysis, and COSAN S. A. (São Paulo, Brazil) for supplying the sugarcane waste ash.

\section{References}

[1] Conab-Companhia Nacional de Abastecimento/Acompanhamento da safra brasileira: Cana-de-açúcar, Terceiro levantamento, V. 3. Safra - no. 3, 2016.
[2] UNICA-União da Indústria de Cana-de-Açúcar (Bioeletricidade) http://www.unica.com.br/colunas/470156692036979688/ bioeletricidade-por-cento3A-o-que-falta-para-esta-alternativa/.

[3] A. Sales and S. A. Lima, "Use of Brazilian sugarcane bagasse ash in concrete as sand replacement," Waste Management, vol. 30, no. 6, pp. 1114-1122, 2010.

[4] G. C. Cordeiro, R. D. Toledo Filho, L. M. Tavares, and E. M. R. Fairbairn, "Pozzolanic activity and filler effect of sugar cane bagasse ash in Portland cement and lime mortars," Cement and Concrete Composites, vol. 30, no. 5, pp. 410-418, 2008.

[5] G. C. Cordeiro, R. D. Toledo Filho, L. M. Tavares, and E. D. M. R. Fairbairn, "Ultrafine grinding of sugar cane bagasse ash for application as pozzolanic admixture in concrete," Cement and Concrete Research, vol. 39, no. 2, pp. 110-115, 2009.

[6] Y. Wang, A. Kalinina, T. Sun, and B. Nowack, "Probabilistic modeling of the flows and environmental risks of nano-silica," Science of the Total Environment, vol. 545-546, pp. 67-76, 2016.

[7] S. R. Kamath and A. Proctor, "Silica gel from rice hull ash: preparation and characterization," Cereal Chemistry, vol. 75, no. 4, pp. 484-487, 1998.

[8] U. Kalapathy, A. Proctor, and J. Shultz, "A simple method for production of pure silica from rice hull ash," Bioresource Technology, vol. 73, no. 3, pp. 257-262, 2000.

[9] U. Kalapathy, A. Proctor, and J. Shultz, "Production and properties of flexible sodium silicate films from rice hull ash silica," Bioresource Technology, vol. 72, no. 2, pp. 99-106, 2000.

[10] U. Kalapathy, A. Proctor, and J. Shultz, "An improved method for production of silica from rice hull ash," Bioresource Technology, vol. 85, no. 3, pp. 285-289, 2002.

[11] L. S. Ferret, "Obtenção de zeólitas e sílica de cinzas de carvão," Anais do V Congresso Brasileiro de Carvão Mineral, ISBN: 97885-66380-02-6, Editora SATC (Educação \& Tecnologia), Gramado, RS, Brazil, pp. 404-409, 2013.

[12] T. C. R. Bertolini, J. C. Izidoro, R. R. Alcântara, L. C. Grosche, and D. A. Fungaro, "Surfactant-modified zeolites from coal fly and bottom ash as adsorbents for removal of crystal violet from aqueous solution," ActaVilet, vol. 1, no. 4, pp. 78-94, 2015.

[13] D. L. Anderson, "Soil and leaf nutrient interactions following application of calcium silicate slag to sugarcane," Fertilizer Research, vol. 30, no. 1, pp. 9-18, 1991.

[14] A. G. Sangster, M. J. Hodson, and H. J. Tubb, "Silicon deposition in higher plants," in Silicon in Agriculture, G. H. Datnoff and G. H. Snyder, Eds., vol. 8, pp. 85-113, Elsevier, 2001.

[15] V. V. Matichenkov and D. V. Calvert, "Silicon as a beneficial element for sugarcane," Journal of the American Society of Sugar Cane Technologists, vol. 22, pp. 21-30, 2002.

[16] R. J. Schaetzl and S. Anderson New York: Cambridge University Press, New York, NY, USA, 2005.

[17] B. T. Tubana and J. R. Heckman, "Silicon in soils and plants," in Silicon and Plant Diseases, F. A. Rodrigues and L. E. Datnoff, Eds., chapter 2, pp. 7-51, Springer International Publishing, Switzerland, Europe, 2015.

[18] J. S. Le Blond, C. J. Horwell, B. J. Williamson, and C. Oppenheimer, "Generation of crystalline silica from sugarcane burning," Journal of Environmental Monitoring, vol. 12, no. 7, pp. 1459-1470, 2010.

[19] A. Sdiri, T. Higashi, S. Bouaziz, and M. Benzina, "Synthesis and characterization of silica gel from siliceous sands of southern Tunisia," Arabian Journal of Chemistry, vol. 7, no. 4, pp. 486493, 2014. 
[20] L. Franken, L. S. Santos, E. B. Caramão, T. M. H. Costa, and E. V. Benvenutti, "Xerogel p-anisidinapropilsílica: estudo da estabilidade térmica e da resistência à lixiviação com solventes," Química Nova, vol. 25, no. 4, pp. 563-566, 2002.

[21] M. A. Girsova, G. F. Golovina, I. A. Drozdova, I. G. Polyakova, and T. V. Antropova, "Infrared studies and spectral properties of photochromic high silica glasses," Optica Applicata, vol. 44, no. 2, pp. 337-344, 2014.

[22] H. Wanyika, E. Maina, A. Gachanja, and D. Marika, "Instrumental characterization of montmorillonite clays by X-ray fluorescence spectroscopy, fourier transform infrared spectroscopy, X-ray diffraction and uv/visible spectrophotometry," Jomo Kenyatta University of Agriculture and Technology, vol. 17, no. 1, pp. 224-239, 2016.

[23] S. Hu and Y.-L. Hsieh, "Preparation of activated carbon and silica particles from rice straw," ACS Sustainable Chemistry and Engineering, vol. 2, no. 4, pp. 726-734, 2014.

[24] A. Mourhly, M. Khachani, A. E. Hamidi, M. Kacimi, M. Halim, and S. Arsalane, "The Synthesis and characterization of low-cost mesoporous silica $\mathrm{SiO}_{2}$ from local pumice rock," Nanomaterials and Nanotechnology, vol. 5, no. 35, pp. 1-7, 2015.

[25] A. F. Boza, V. L. Kupfer, A. R. Oliveira et al., "Synthesis of $\alpha$-aminophosphonates using a mesoporous silica catalyst produced from sugarcane bagasse ash," RSC Advances, vol. 6, no. 29, pp. 23981-23986, 2016.

[26] A. F. Hassan, A. M. Abdelghny, H. Elhadidy, and A. M. Youssef, "Synthesis and characterization of high surface area nanosilica from rice husk ash by surfactant-free sol—gel method," Journal of Sol-Gel Science and Technology, vol. 69, no. 3, pp. 465-472, 2014.

[27] P. Su, R. Wang, Y. Yu, and Y. Yang, "Microwave-assisted synthesis of ionic liquid-modified silica as a sorbent for the solid-phase extraction of phenolic compounds from water," Analytical Methods, vol. 6, no. 3, pp. 704-709, 2014.

[28] P. L. King, P. F. McMillan, and G. M. Moore, "Infrared spectroscopy of silicate glasses with application to natural systems," Infrared Spectroscopy of Silicate Glasses with Application to Natural Systems, Chapter 4, pp. 93-134, 2004.

[29] R. Yuvakkumar, V. Elango, V. Rajendran, and N. Kannan, "High-purity nano silica powder from rice husk using a simple chemical method," Journal of Experimental Nanoscience, vol. 9, no. 3, pp. 272-281, 2014.

[30] L. H. Jones, "Infrared spectra and structure of the crystalline sodium acetate complexes of $\mathrm{U}(\mathrm{VI}), \mathrm{Np}(\mathrm{VI}), \mathrm{Pu}(\mathrm{VI})$, and Am(VI). A comparison of metal-oxygen bond distance and bond force constant in this series," The Journal of Chemical Physics, vol. 23, no. 11, pp. 2105-2107, 1955.

[31] K. S. Sing, "Reporting physisorption data for gas/solid systems with special reference to the determination of surface area and porosity (Recommendations 1984)," Pure and Applied Chemistry, vol. 57, no. 4, pp. 603-619, 1985.

[32] J. Rouquerol and F. Rouquerol, "Adsorption at the liquid-solid interface: thermodynamics and methodology.," in Adsorption by Powders and Porous Solids (Second Edition), F. R. R. S. W. S. L. Maurin, Ed., pp. 105-158, Academic Press: Oxford, 2014.

[33] K. S. W. Sing, "Reporting physisorption data for gas/solid systems with special reference to the determination of surface area and porosity (Provisional)," Pure and Applied Chemistry, Pergamon Press, vol. 54, no. 11, pp. 2201-2218, 1982.
[34] S. D. Bhagat, Y.-H. Kim, M.-J. Moon, Y.-S. Ahn, and J.-G. Yeo, "A cost-effective and fast synthesis of nanoporous $\mathrm{SiO}_{2}$ aerogel powders using water-glass via ambient pressure drying route," Solid State Sciences, vol. 9, no. 7, pp. 628-635, 2007. 

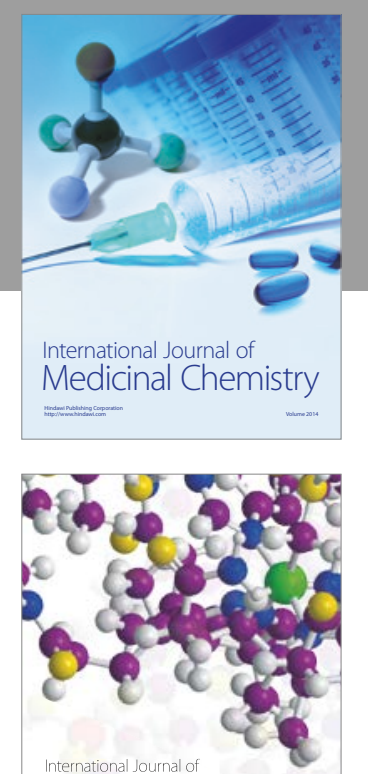

Carbohydrate Chemistry

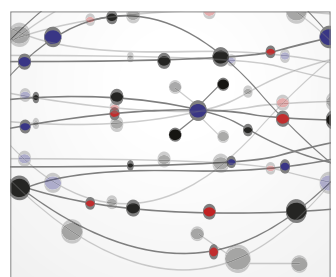

The Scientific World Journal
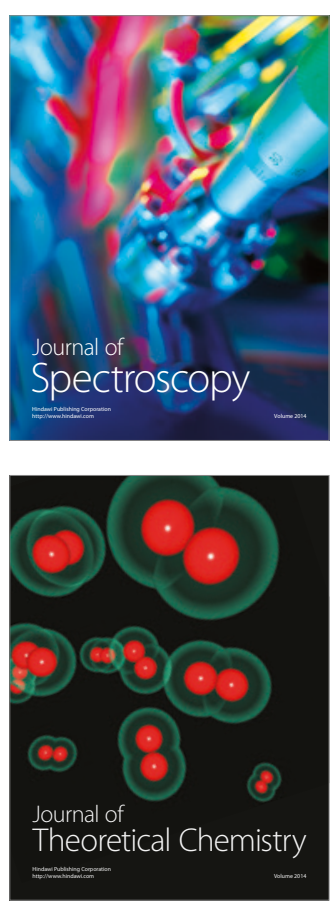
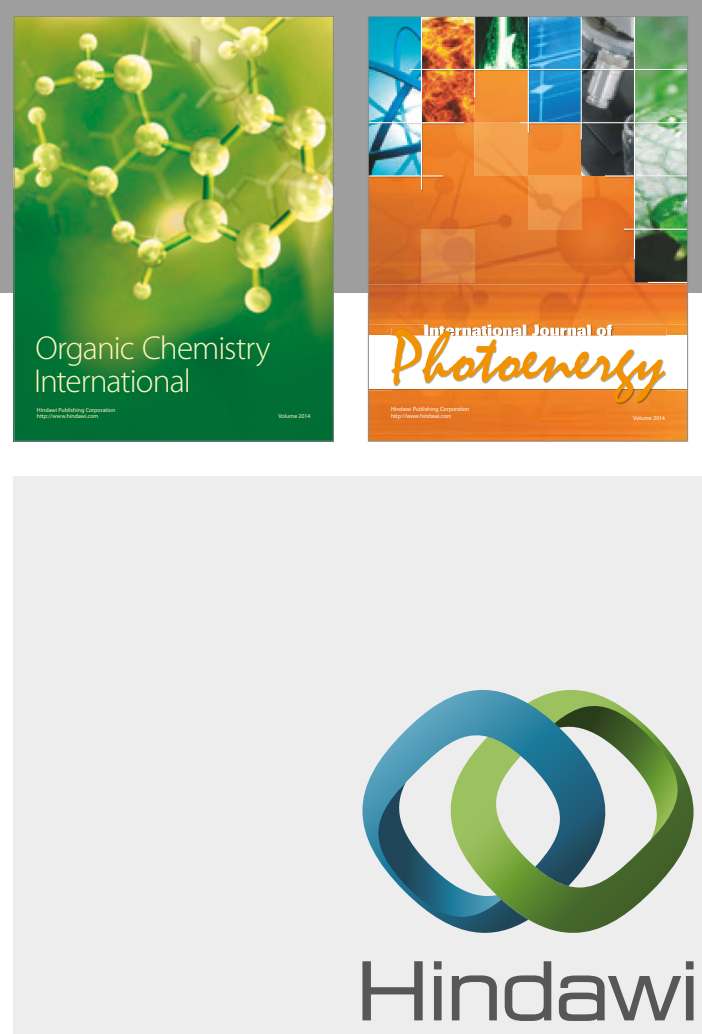

Submit your manuscripts at

https://www.hindawi.com

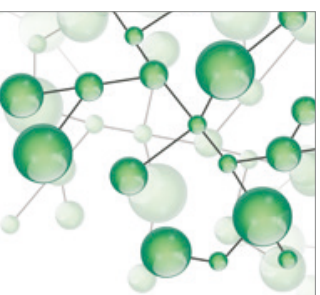

International Journal of

Inorganic Chemistry

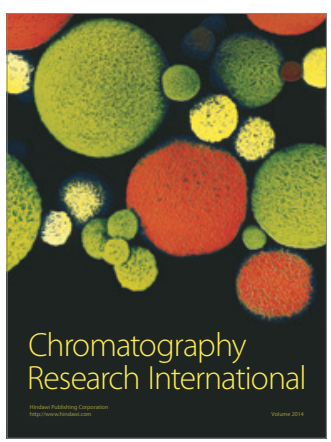

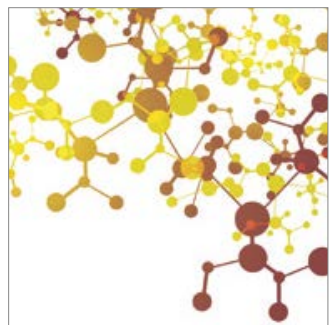

Applied Chemistry
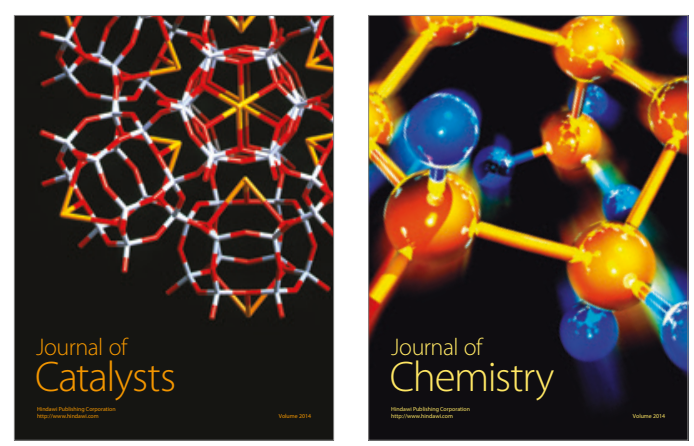
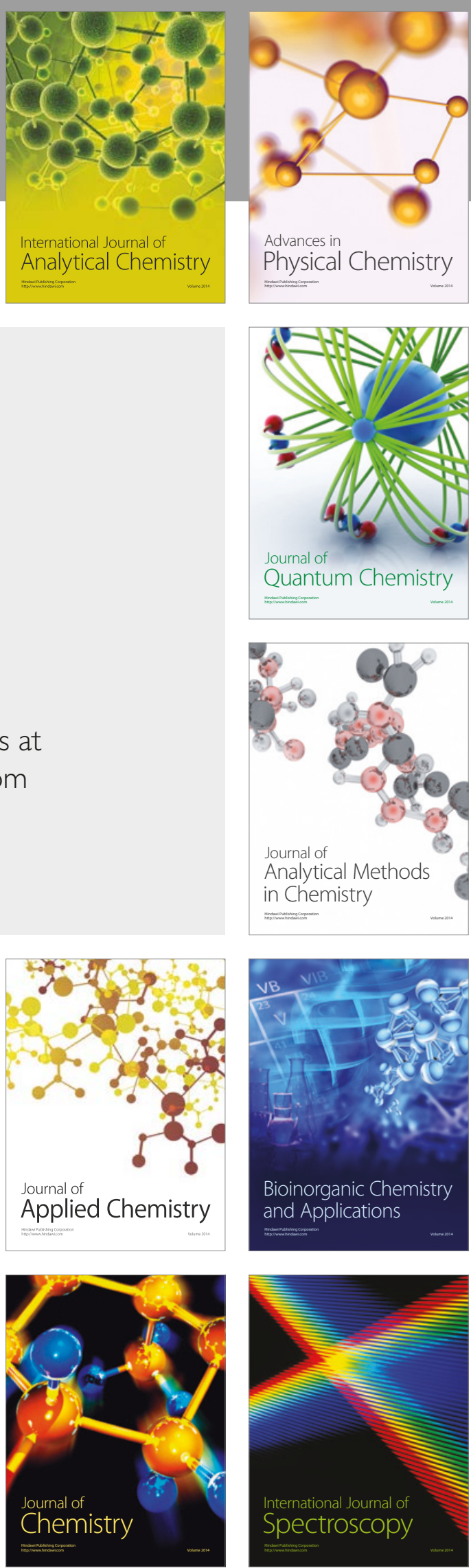